\title{
The Timing of Middle-Childhood Peer Rejection and Friendship: Linking Early Behavior to Early-Adolescent Adjustment
}

\author{
Sara Pedersen, Frank Vitaro, and \\ Edward D. Barker \\ University of Montreal
}

\author{
Anne I. H. Borge \\ University of Oslo
}

\begin{abstract}
This study used a sample of 551 children surveyed yearly from ages 6 to 13 to examine the longitudinal associations among early behavior, middle-childhood peer rejection and friendedness, and early-adolescent depressive symptoms, loneliness, and delinquency. The study tested a sequential mediation hypothesis in which (a) behavior problems in the early school years are associated with middle-childhood peer rejection and (b) rejection, in turn, leads to lower friendedness and subsequently higher adolescent internalizing-but not externalizing-problems. Results supported this sequential mediation model for internalizing outcomes and revealed an additional path from early disruptiveness to loneliness via peer rejection alone. No evidence of sequential mediation was observed for delinquency.
\end{abstract}

Problematic peer relations, such as peer rejection, are associated with a variety of developmental and psychological difficulties in childhood and adolescence (Rubin, Bukowski, \& Parker, 1998). Rejected children are at risk for negative outcomes in a broad spectrum of developmental domains, including behavioral adjustment, academics, and psychological well-being (Deater-Deckard, 2001; Parker \& Asher, 1987). Several studies have documented the link between peer rejection and childhood externalizing problems, such as antisocial behavior (for reviews, see Boivin, Vitaro, \& Poulin, 2005; Rubin et al., 1998). Some studies have also shown that peer rejection is associated with heightened risk for internalizing problems in childhood, including depressed mood and loneliness (Boivin, Poulin, \& Vitaro, 1994; Ladd \& Troop-Gordon, 2003; Lopez \& DuBois, 2005; McDougall, Hymel, Vaillancourt, \& Mercer, 2001; Ollendick, Weist, Borden, \& Greene, 1992; Panak \& Garber, 1992; Parker \& Asher, 1987; Parker, Saxon, Asher, \& Kovacs, 1999).

The pathways linking peer rejection and other childhood peer processes to internalizing and externalizing problems in early adolescence, however, are less clear. More specifically, the importance of the timing of childhood rejection relative to other

This research was made possible by a grant from the Social Sciences and Humanities Research Council of Canada. We thank the authorities and directors of schools in the Val d'Or School Board and the participating teachers and students. We also thank Ryan E. Adams for his helpful suggestions on a previous draft of this manuscript.

Correspondence concerning this article should be addressed to Sara Pedersen, Research Unit on Children's Psychosocial Maladjustment, University of Montreal, 3050 Edouard Montpetit Boulevard, Montreal, QC H3T 1J7, Canada. Electronic mail may be sent to sara.pedersen@umontreal.ca. peer-related experiences for subsequent functioning has yet to be determined. In other words, does childhood rejection lead directly to early-adolescent dysfunction regardless of when that rejection is experienced? Or is there a point in middle childhood at which rejection is most risky, perhaps because it contributes to other negative peer-related experiences, which in turn contribute to early-adolescent dysfunction?

Indeed, the research suggests peer rejection does not act alone in influencing development into early adolescence. Peer rejection at the group level is only one of many aspects of childhood peer relationships that affect well-being. Friendships may also influence child outcomes. Although peer rejection and the development of dyadic friendships are to some degree interrelated, they are conceptually distinct constructs (Asher, Parker, \& Walker, 1996; Bukowski \& Hoza, 1989). Many rejected children maintain at least one close, reciprocal friendship and some popular children have no reciprocal friendships (Asher \& Paquette, 2003; Parker \& Asher, 1993). As such, rejection and friendedness-the extent to which a child has more or fewer friends in his or her network-could constitute separate or parallel pathways to adjustment in early adolescence. For example, Parker and Asher (1993) found that having a reciprocal best friend was negatively related to loneliness even after adjusting for peer acceptance.

Because peer rejection and friendedness are interrelated, it is also possible that these two peer experiences constitute a sequentially mediated pathway to

(C) 2007 by the Society for Research in Child Development, Inc. All rights reserved. 0009-3920/2007/7804-0001 
early-adolescent adjustment. In particular, the relative timing of peer rejection and friendedness in childhood may be key to understanding the mechanism by which these two peer experiences affect subsequent functioning. Sullivan (1953) emphasized the importance of "chumships," or close, dyadic friendships, during the preadolescent period of ages 8 to 11. In this stage of development, also referred to as middle childhood, children form strong attachments to friends and begin to value intimacy and reciprocity in these relationships. As Berndt (2004) pointed out, however, friendships do not suddenly emerge at age 8 but grow slowly in importance and intimacy into early adolescence. Peer rejection during the early part of this critical period for friendship formation may set the stage for low friendedness in the following years. For example, peer rejection may foster difficulties in establishing friendships because rejected children are avoided by other children due to the rejected child's negative reputation. Rejected status may also limit opportunities to socialize and become friends with other children during unstructured classroom time, at recess, or after school. Low friendedness, in turn, may affect adjustment into early adolescence. Indeed, peer acceptance is thought to foster the development of high-quality friendships that enhance developmental outcomes (Demir \& Urberg, 2004; Nangle, Erdley, Newman, Mason, \& Carpenter, 2003). Conversely, peer rejection may contribute to difficulties in establishing these high-quality, development-enhancing friendships.

An alternate sequentially mediated pathway, in which low friendedness contributes to peer rejection and, in turn, to adolescent adjustment is also possible. The alternate pathway, however, tends to receive less support in the theoretical and empirical literatures. Although both rejection and friendedness can be experienced throughout childhood and are interrelated throughout childhood, the psychological impact of each experience may differ depending on the child's developmental stage. For example, both peer acceptance and friendedness have been shown to be relatively stable during childhood but, depending on the child's age, differ in terms of importance for the child's well-being (Brendgen, Vitaro, Bukowski, Doyle, \& Markiewicz, 2001; Gifford-Smith \& Brownell, 2003). Gifford-Smith and Brownell's (2003) review of the literature on childhood peer relations indicates that peer acceptance is most critical early in elementary school but decreases in importance thereafter. By middle to late childhood, friendships are more central to the child's healthy development. These findings suggest that, relative to rejection, late childhood friendedness should be more strongly related to early-adolescent adjustment. Thus, to the degree that peer rejection and friendship form a mediating pathway to adjustment, this pathway is more likely to take the form of rejection affecting adjustment through friendedness than friendedness affecting adjustment through rejection.

The extent to which peer rejection and friendedness contribute to early-adolescent adjustment via parallel pathways or the sequential mediation pathway, however, may vary depending on the type of indicators used to assess adjustment. Several studies have identified links between peer rejection or friendedness and indicators of internalizing problems, including depressive symptoms and loneliness (e.g., Boivin et al., 1994; Kiesner, 2002; Ladd \& TroopGordon, 2003; Panak \& Garber, 1992). Friendships have also been found to play a role in the processes leading to internalizing problems (Nangle et al., 2003).

On the other hand, the roles played by rejection and friendedness in predicting early-adolescent externalizing problems are less clear. Although disruptive behaviors are clearly related to a heightened risk of rejection and friendlessness in childhood (Coie \& Dodge, 1998; Rubin et al., 1998), the strength of these associations declines markedly as children enter early adolescence (Boivin, Hymel, \& Hodges, 2001). Some authors have found that problem behaviors may even receive support from the early-adolescent peer group (Alexander, Piazza, Mekos, \& Valente, 2001; Allen, Porter, McFarland, Marsh, \& McElhaney, 2005; Prinstein \& Cillessen, 2003), whereas others have reported that externalizing problems, including delinquency and drug use, are unrelated to peer rejection in late childhood and early adolescence (Dishion, Capaldi, Spracklen, \& Li, 1995; Ladd, 2006).

Delinquent behaviors have also been found to require the company of friends (Lacourse, Nagin, Tremblay, Vitaro, \& Claes, 2003; Patterson, Dishion, \& Yoerger, 2000). Hence, to the degree that rejection inhibits friendship formation-especially the formation of friendships with deviant peers-the low friendedness that could result from early peer rejection may actually lead rejected children to exhibit less delinquency and drug use than their accepted peers. Indirect evidence in support of the role of friendedness in the pathway linking early rejection to later delinquency and drug use comes from two studies by Vitaro and his colleagues (Vitaro, Brendgen, \& Wanner, 2005; Vitaro, Tremblay, Kerr, Pagani, \& Bukowski, 1997). In both studies, the authors found that disruptive children with no friends reported less delinquency than children with disruptive friends (although the disruptive, low-friended children 
reported more delinquency than children with nondisruptive friends). Other studies also suggest that friendship stability and friends' characteristics, such as deviant behavior, are better predictors of adolescent externalizing problems than the presence or absence of friends (e.g., Agnew, 1991; Berndt, Hawkins, \& Jiao, 1999). Studies that examined friendedness - and not friends' characteristics or friendship quality-in middle childhood have also found friendedness to be unrelated to externalizing problems (e.g., Ladd \& Troop-Gordon, 2003).

No empirical investigations, however, have tested the sequential (or alternate sequential) mediation hypothesis for specificity to internalizing or externalizing outcomes. The few studies that have attempted to test this hypothesis have targeted only internalizing problems. These studies have yielded conflicting findings. In a cross-sectional study, Nangle et al. (2003) found support for a model in which friendedness and friendship quality fully mediate the association between popularity (a construct often characterized as the opposite of rejection) and loneliness in children. In contrast, Demir and Urberg (2004) found no bivariate association between acceptance and depressed mood in their adolescent sample. This finding does not, however, necessarily conflict with the sequential mediation hypothesis. Indeed, the finding is consistent with prior research that suggests that the bivariate link between peer acceptance and mood states is stronger in childhood and attenuates during adolescence (Boivin et al., 1994; Bukowski, Pizzamiglio, Newcomb, \& Hoza, 1996). If measured earlier in development, peer rejection and friendship experiences may still predict adolescent mood states.

Past studies have also failed to illuminate how the timing of rejection and friendship formation during childhood may affect internalizing and externalizing problems differently. For example, few studies have examined more than one peer experience at a time (Gifford-Smith \& Brownell, 2003). Hence, no study has examined the interrelations among dyadic and group-level childhood peer processes over time and established how, together or separately, these peer processes influence adolescent adjustment. Ladd and Troop-Gordon (2003) found that rejection in Grades 1-3 predicted Grade 4 loneliness, internalizing problems, and externalizing problems, whereas Grade 1 3 friendlessness predicted only loneliness and internalizing problems. These findings, however, have not been extended to early adolescence. Therefore, it remains unclear whether the associations between childhood peer processes and adjustment are consistent throughout development or specific to childhood. In addition, although this study established that rejection in Grades 1-3 predicts Grade 4 friendlessness, it also remains unclear whether friendlessness, in turn, predicts internalizing or externalizing problems later in development.

Furthermore, studies that have assessed the possible mediating role of friendedness in child and adolescent development (e.g., Nangle et al., 2003) tend to be cross-sectional, which is an important limitation for showing any sequential ordering of the two peer experiences relative to the adjustment outcome. Rejection and friendedness could result from adjustment as much as they contribute to adjustment. Even the few longitudinal investigations of the effects of dyadic or group-level peer relations on development that are available in the literature tend to have short time frames of just a few years (e.g., DeRosier, Kupersmidt, \& Patterson, 1994) or focus on a single developmental period (e.g., Ladd \& TroopGordon, 2003).

Finally, studies have rarely examined the contribution of early, stable characteristics of the child, such as social withdrawal or disruptive behaviors, that may set the stage for peer rejection and low friendedness. Early anxious and socially withdrawn behaviors can both contribute to peer rejection and limit children's opportunities to form friendships (Panak \& Garber, 1992). For example, in a cross-sectional study with a middle-childhood sample, Boivin and Hymel (1997) identified an association between anxietysocial withdrawal and concurrent peer-rated social preference. Disruptive behaviors have also been linked to childhood peer processes. Laird, Jordan, Dodge, Pettit, and Bates (2001) used a diverse sample of children to identify a positive relation between early behavior problems and chronic rejection in the first 4 years of schooling. Boivin and Hymel also found an association between aggression and social preference in middle childhood. Finally, Ladd and Troop-Gordon (2003) linked early disruptive behaviors not only to rejection but also to friendedness in the early school years.

The current study attempts to clarify the nature of the relations among early behavioral risk factors, childhood peer and friendship experiences, and early-adolescent internalizing and externalizing problems. To capture the dynamic interrelations between peer rejection and friendedness throughout middle childhood, peer rejection and friendedness indicators were grouped into two 2-year intervals. The first interval covered ages 8 and 9 years and the second interval covered ages 10 and 11 . Together, the data span the period suggested by Sullivan (1953) as critical to friendship formation and by other authors as the time at which change may be observed in the 
relative importance of rejection at the group level and the absence of friends at the dyadic level for individual adjustment (Gifford-Smith \& Brownell, 2003). The early behavior indicators (anxiety - social withdrawal and disruptive behavior) and the three earlyadolescent outcomes (depressive symptoms, loneliness, and delinquency) were also grouped into 2-year intervals (ages $6-7$ and $12-13$ ).

The study aims to answer the following questions: What are the indirect pathways that link early behavior, middle-childhood peer processes, and earlyadolescent development? More specifically, does early behavior predict middle-childhood rejection and friendedness? How are peer rejection and friendedness interrelated during middle childhood? Do these peer processes act independently as additive risk factors or parallel mediators of the association between early behavior and adjustment? Or is there support for a sequential mediating pathway in which early behavioral risk leads to peer rejection at the start of the critical phase for friendship formation, inhibiting the development of reciprocal friendships in middle childhood and, ultimately, contributing to risky adolescent outcomes? Alternately, does low friendedness early in middle childhood contribute to later rejection and, subsequently, to adolescent functioning? Finally, are these observed pathways specific to the type of adolescent outcome under consideration? In other words, do similar mediation pathways link early behavior to early-adolescent internalizing and externalizing outcomes?

\section{Method}

\section{Sample}

Participants in the present study were 551 French Canadian children (301 boys, 250 girls) from a small community in northwestern Quebec, Canada (population 30,000). They attended five elementary schools from kindergarten up to Grade 6, after which they transferred to one large high school. The elementary schools were homogeneous in size, characteristics of the children in the classes, and neighborhood characteristics. All French-speaking children in the community were targeted for study in each year of data collection, beginning in kindergarten (19861987). At least $90 \%$ of the children in the targeted classrooms participated in the study in each year. The current study uses data collected across 8 years from when the children were in kindergarten $(M$ age $=6.10$ years, $S D=.30)$ to when they were in seventh grade $(M$ age $=13.09$ years, $S D=.30)$.
Children who did not participate did not receive parental permission or were absent from school on the day of data collection. Additional attrition occurred as children moved away from the area with their families. To be included in the present study, children needed to have information on a minimum of two study variables; 551 children met this criterion. However, only 163 of the 551 children in the final sample had complete data across all variables created for the study. Between $70 \%$ and $84 \%$ of data were available for each study variable. We conducted an attrition analysis in which all demographic covariates, early behavior indicators, and middle-childhood peer process variables were used to predict missingness on the early-adolescent outcome variables in a logistic regression framework. The results suggest that differential attrition did not occur. The omnibus test of the significance of the full model was nonsignificant, $\chi^{2}(8)=12.60, n s$, as was each of the individual parameter estimates.

At kindergarten entry, $80 \%$ of children lived in twoparent families with both biological parents, $12 \%$ lived with the mother only, and $8 \%$ lived in other family configurations. Participants' socioeconomic status (SES) according to the Blishen, Carroll, and Moore (1987) Occupational Prestige Scale (described later; $M=40.75, S D=10.20$ ) was similar to the average score for a representative sample of kindergarten children throughout Quebec $(M=43.74, S D=$ 12.88). Finally, $18 \%$ of the parents had completed high school, $47 \%$ had at least some post-high school education, and $35 \%$ had not graduated from high school.

Each spring (in April or May), participants spent $2 \mathrm{hr}$ of classroom time answering questionnaires. The children were informed about the purpose of the study and were told that all of their answers would be confidential and that they did not have to answer any of the questions if they did not want to. Trained research assistants administered and collected the questionnaires in the absence of classroom teachers. Teachers also completed questionnaires during this period. Parents (mostly mothers) completed questionnaires sent to them by mail around the same time as the data were collected at school.

\section{Measures}

All instruments were administered in French. Instruments that were written originally in English were translated into French and then translated back into English. English-speaking judges verified the semantic similarity between the back-translated items and the original items. 
Sociodemographicinformation. Mother-reported maternal occupation was scored on a continuous scale according to Blishen et al. (1987). This score is based on the average income and average education level associated with occupations in Canada. Maternal occupation scores for each child were averaged across the years of the study in which he or she participated. The mean maternal occupational status across children and waves of data was $40.75(S D=10.20)$.

Anxiety-social withdrawal. Mothers and teachers rated the children's behavior at ages 6 and 7 using five anxiety-social withdrawal items from the Social Behavior Questionnaire (SBQ; Tremblay et al., 1991). Sample items include "is solitary" and "tends to fear new things and new situations." Mothers and teachers indicated whether each item did not apply (0), applied sometimes (1), or applied often (2) to the child. Internal consistency was acceptable, with alphas ranging from .60 to .73 across time and raters. Scores were summed within rater and time; values ranged from 0 and 10 for mother and teacher ratings at each time point.

Mother-rated anxiety - social withdrawal scores at ages 6 and 7 were correlated $(r=.56, p<.001)$, as were teacher-rated anxiety-social withdrawal scores $(r=$ $.23, p<.001)$. In addition, mean mother-rated and teacher-rated anxiety-social withdrawal scores were correlated $(r=.25, p<.001)$. Because the correlation between the mean maternal and teacher reports of anxiety-social withdrawal and the stability of teacher-rated anxiety-social withdrawal were low to moderate in size, all analyses presented here were also conducted using only mother-reported values. The results were nearly identical to those obtained when the combined maternal and teacher reports were used. We present the results using the combined scores to maintain consistency with the measurement of disruptiveness, the other early behavioral indicator. The mean value across time and raters was 2.64 $(S D=1.42)$.

Disruptive behavior. Mothers and teachers rated children's behavior at ages 6 and 7 using 13 disruptiveness items from the SBQ (Tremblay et al., 1991). The disruptiveness items covered physical aggression, opposition, hyperactivity, and antisociality (i.e., lying, cheating, stealing). Exploratory and confirmatory factor analyses suggested that these items belonged to a single factor for children of this age (Rubin, Moller, \& Emptage, 1986; Tremblay, Vitaro, Gagnon, Piché, \& Royer, 1992). Mothers and teachers indicated whether each item did not apply (0), applied sometimes (1), or applied often (2) to the child. Internal consistency was high, with alphas of .86 to .89 across time and raters. Values for the summed disruptive- ness scores ranged from 0 to 24 for teacher and mother ratings at each time point.

Mother-rated disruptiveness scores at ages 6 and 7 were correlated $(r=.70, p<.001)$, as were teacherrated disruptiveness scores $(r=.53, p<.001)$. In addition, mean mother-rated and teacher-rated disruptiveness scores were correlated $(r=.47, p<.001)$. Values were averaged across time and raters to achieve more stable estimates of disruptiveness $(M=5.35, S D=3.49)$.

Peer rejection. Children's sociometric status was assessed from ages 8 through 11 through peer nominations. Specifically, names of all children in a given class were handed out to the participants. Two research assistants ensured that all participants recognized the names of all classmates by reading them aloud in front of the class. The children were then asked to circle the names of the three children they liked most (positive nominations) and the three children they liked least (negative nominations). Criteria outlined by Coie, Dodge, and Coppotelli (1982) were used to compute the sociometric status for each participant in each year.

The number of years children were in the rejected category was computed for two 2-year intervals (i.e., ages $8-9$ and 10-11). Values ranged from 0 (never rejected) to 2 (rejected at both time points). The mean value across ages 8 and 9 was $.25(S D=.47)$ and across ages 10 and 11 was $.24(S D=.46)$. Both variables were transformed using an inverse transformation to improve their distributional characteristics (ages 8-9: $M=.87, S D=.21$; ages $10-11: M=.88, S D=.21$ ).

Please note that because inverse transformations of the peer rejection variables were used, the estimates presented in the results are opposite in sign to those produced by the analyses (i.e., we present the associations between peer rejection and other variables rather than the associations between the inverse of peer rejection and other variables). The signs are reversed for ease of presentation and interpretation of the results.

Friendedness. Children were also asked to nominate up to four best friends in the classroom in each year from ages 8 to 11 . For the purposes of this study, only reciprocal friends-when the nominated friend also nominated the target child as one of his or her four best friends (Bukowski \& Hoza, 1989)—were used. The mean numbers of reciprocal friends across ages 8 and 9 and across ages 10 and 11 were calculated. Children had an average of 1.05 reciprocal friends across ages 8 and $9(S D=.85)$ and an average of 1.28 reciprocal friends at ages 10 to $11(S D=1.00$; skewness $=.47$, kurtosis $=-.57$ ). The vast majority of these friends were of the same sex as the target child. 
At each wave, only $1 \%$ to $4 \%$ of children had one or more reciprocated other-sex friends.

Depressive symptoms. Study participants completed the Children's Depression Inventory (CDI; Kovacs, 1992) at ages 12 and 13. The CDI is a 27-item scale assessing self-reported symptoms of depression. The suicidal ideation item was not used in the current study because of concerns by the school administration. Individual item scores ranged from 0 to 2 with higher ratings indicating more severe symptoms. The CDI has relatively high internal consistency and stability and has been validated using normative and clinic-referred samples (Fundulis et al., 1991). The score on the CDI was calculated by summing the 26 individual item scores at each wave and then taking the mean of these two summed scores $(M=$ $9.85, S D=6.47$, skewness $=.91$, kurtosis $=.56$ ). The scale exhibited high internal consistency at each wave ( $\alpha$ s $=.85$ and .87 ).

Loneliness-social dissatisfaction. Participants' feelings of loneliness and social dissatisfaction were assessed at ages 12 and 13 using a 16-item self-report measure developed by Asher, Hymel, and Renshaw (1984). This scale has been found to be reliable and valid in other studies (Asher \& Wheeler, 1985) and exhibited high internal consistency at each wave of data collection in the current study ( $\alpha \mathrm{s}=.75$ and .82 ). Scores on the loneliness-social dissatisfaction scale were calculated by taking the mean of the items at each wave and the mean of the two average wave scores. The variable was then transformed using a log transformation to improve its distributional characteristics $(M=.88, S D=.28)$.

Delinquency. Involvement in delinquent behaviors was assessed at ages 12 and 13 using the 25-item Self-Reported Delinquency Questionnaire (SRDQ;
LeBlanc \& Fréchette, 1989). The validity of selfreported measures of delinquency and drug use has been documented in several studies (Hindelang, Hirschi, \& Weiss, 1981; Klein, 1989). At each time of assessment, the participants reported whether they had been involved in a variety of delinquent behaviors, such as interpersonal violence (e.g., "Used a weapon during a fight with another person"), vandalism (e.g., "Broken or destroyed something that did not belong to you"), theft (e.g., "Taken and kept something in a store without paying"), and substance use (e.g., "Used marijuana") over the past 12 months. Response options ranged from never (1) to often (4). In the current study, the SRDQ exhibited high internal consistency across waves ( $\alpha$ s $=.84$ and .92$)$. Scores were averaged within and across waves. The mean delinquency score was then transformed using a log transformation to improve its distributional characteristics $(M=1.48, S D=.08)$.

\section{Results}

\section{Bivariate Associations}

First, bivariate correlations among all study variables were examined (see Table 1). Relations of sex and maternal occupational prestige with the other study variables support the inclusion of these two variables as covariates in the path models tested in the current study. Girls were less disruptive, less likely to be rejected, and tended to have more reciprocal friends than boys. Girls also reported more depressive symptoms and less delinquency. Maternal occupational status was inversely related to disruptiveness and peer rejection and positively related to friendedness.

Table 1

Bivariate Correlations Among All Study Variables (Age)

\begin{tabular}{|c|c|c|c|c|c|c|c|c|c|c|}
\hline & 1 & 2 & 3 & 4 & 5 & 6 & 7 & 8 & 9 & 10 \\
\hline \multicolumn{11}{|l|}{ 1. $\operatorname{Sex}(0=$ boys, $1=$ girls $)$} \\
\hline 2. Maternal occupational prestige & -0.04 & & & & & & & & & \\
\hline 3. Disruptiveness $(6-7)$ & $-0.31^{*}$ & $-0.15^{*}$ & & & & & & & & \\
\hline 4. Anxiety-social withdrawal $(6-7)$ & -0.08 & -0.07 & $0.17^{*}$ & & & & & & & \\
\hline 5. Peer rejection $(8-9)$ & $-0.16^{*}$ & $-0.16^{*}$ & $0.38^{*}$ & $0.10 *$ & & & & & & \\
\hline 6. Peer rejection $(10-11)$ & $-0.10^{*}$ & $-0.13^{*}$ & $0.32 *$ & 0.06 & $0.45^{*}$ & & & & & \\
\hline 7. Number of friends $(8-9)$ & $0.10^{*}$ & -0.01 & $-0.19^{*}$ & $-0.20^{*}$ & $-0.29 *$ & $-0.22 *$ & & & & \\
\hline 8. Number of friends $(10-11)$ & 0.06 & $0.12^{*}$ & $-0.17^{*}$ & -0.03 & $-0.29 *$ & $-0.31^{*}$ & $0.35^{*}$ & & & \\
\hline 9. Depressive symptoms $(12-13)$ & $0.15^{*}$ & $-0.16^{*}$ & 0.10 & $0.12 *$ & 0.05 & $0.10^{*}$ & $-0.18^{*}$ & $-0.13^{*}$ & & \\
\hline 10. Loneliness $(12-13)$ & -0.03 & $-0.11^{*}$ & $0.13^{*}$ & $0.12 *$ & 0.10 & $0.27^{*}$ & $-0.14^{*}$ & $-0.17^{*}$ & $0.41^{*}$ & \\
\hline 11. Delinquency $(12-13)$ & $-0.12^{*}$ & $-0.11^{*}$ & $0.24 *$ & -0.01 & 0.07 & 0.07 & -0.01 & -0.07 & $0.39 *$ & 0.03 \\
\hline
\end{tabular}

$* p<.05$. 
Maternal occupational status was also associated with fewer depressive symptoms, less loneliness, and less delinquency.

Associations of early behavior indicators with each other, the middle-childhood peer processes, and early-adolescent outcomes tended to be in the expected directions. Disruptiveness and anxiety-social withdrawal were positively correlated. Furthermore, disruptiveness was positively related to rejection, loneliness, and delinquency and negatively related to friendedness. Anxiety-social withdrawal was positively associated with rejection, depressive symptoms, and loneliness and negatively associated with friendedness.

The middle-childhood peer process variables also tended to be associated with each other and the earlyadolescent internalizing outcomes. Peer rejection at ages $8-9$ was positively related to rejection at ages $10-11$. Similarly, friendedness at ages $8-9$ and $10-11$ were positively correlated. Peer rejection and friendship were negatively correlated within and across time. For the adolescent outcomes, later rejection was positively related to loneliness. Friendedness at each interval was negatively related to depressive symptoms and loneliness. Finally, depressive symptoms were positively correlated with loneliness and delinquency. Loneliness and delinquency were unrelated.

\section{Model Testing}

We first used the bivariate correlations among the study variables to test the equivalence of the variance-covariance matrix across the two sexes. Using Mplus 3.11 (Muthén \& Muthén, 2004), we tested a two-group model in which the correlations among all study variables except gender were assessed and constrained to be the same for boys and girls. Means and variances were allowed to vary across groups. Missing values were estimated using a full information maximum likelihood method.
The model fit the data well, $\chi^{2}(45)=50.86, n s$; comparative fit index (CFI) $=.99$, Tucker-Lewis index $(\mathrm{TLI})=.98$, root mean square error of approximation (RMSEA) $=.02$ (Hu \& Bentler, 1999). The nonsignificant chi-square value indicates that this model does not fit significantly worse than the fully saturated model in which all correlations are free to vary across the two groups. This finding indicates that the relations among the study variables are the same for boys and girls.

Next, a series of path models were estimated. Observed variables included in these models were the demographic covariates (sex and maternal occupational prestige), the two early behavioral predictors (disruptiveness and anxiety-social withdrawal), the middle-childhood predictors (rejection and friendedness at ages $8-9$ and 10-11), and the three adolescent outcomes (depressive symptoms, loneliness, and delinquency). Again, missing values were estimated using a full information maximum likelihood method.

Our model-building strategy was to compare the fit of nested models including a fully estimated model and a restricted model. For each outcome, we first tested a full model (see Figure 1). Early disruptiveness and anxiety - social withdrawal (ages 6-7) were used to predict peer rejection and friendedness at ages $8-9$. Each of these age 8-9 indicators was, in turn, used to predict to the same indicators at ages 10-11. Finally, age 10-11 peer rejection and friendedness were used to predict the adolescent outcome. Following the estimation of the full model, the restricted model, in which paths that were not significant at the trend level or better were eliminated to improve model fit, was estimated. We examined the restricted model for evidence of (a) parallel mediation pathways between the early behavioral characteristics and adolescent adjustment separately through peer rejection and friendedness, (b) a sequential mediation pathway through earlier peer rejection and later

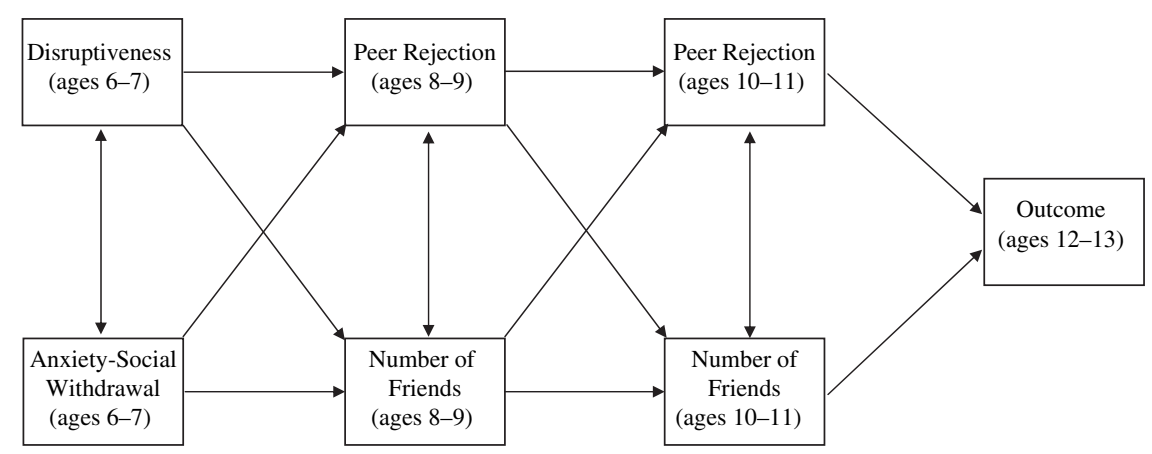

Figure 1. The full model: Links among early behavior, middle-childhood peer rejection and friendship, and early-adolescent outcomes. 
friendedness, and (c) an alternate sequential mediation pathway through earlier friendedness and later peer rejection. The results of the full and restricted models are described next.

\section{Depressive Symptoms}

The full model for depressive symptoms did not fit the data well, $\chi^{2}(8)=25.35, p<.01$; CFI $=.96$, $\mathrm{TLI}=.80$, RMSEA $=.06$. Adding a path linking early disruptiveness to peer rejection at ages $10-11$, as suggested by the modification indexes, and trimming the nonsignificant paths in the model improved the fit, $\chi^{2}(17)=26.11, n s ; \mathrm{CFI}=.98$, TLI $=.95$, RMSEA $=$ .03. This analysis revealed significant associations of the demographic covariates with early disruptiveness, peer rejection at ages 8-9, and depressive symptoms. Standardized estimates are reported unless otherwise noted. Boys were more disruptive than girls in early childhood (estimate $=-.32, p<$ .001) but reported fewer depressive symptoms in early adolescence (estimate $=.15, p<.01$ ). Maternal occupational prestige was inversely related to early disruptiveness (estimate $=-.17, p<.01$ ), peer rejection across ages $8-9$ (estimate $=-.11, p<.05)$, and adolescent depressive symptoms (estimate $=-.13$, $p<.05)$.

Early behavior was associated with both middlechildhood peer processes (see Figure 2). Early disruptiveness was positively related to peer rejection at ages 8-9 and 10-11 (ages 8-9: estimate $=.36, p<$ .001 ; ages $10-11$ : estimate $=.17, p<.01$ ) and negatively related to friendedness at ages $8-9$ (estimate $=-.16, p<.01)$. Anxiety-social withdrawal, however, was only associated with the number of friends at ages $8-9$ (estimate $=-.17, p<.01)$.

Early-adolescent depression was negatively associated with friendedness at ages 10-11 (estimate $=$
$-.13, p<.05)$. In contrast, peer rejection at this age interval did not make an independent and direct contribution to the explanation of variance in depressive symptoms.

The analysis also tested the significance of the indirect pathways from the early behavioral predictors to depressive symptoms. One statistically significant pathway was identified. This pathway provided support for the sequential mediation model. Specifically, the indirect pathway from early disruptiveness to depressive symptoms via peer rejection at ages 8-9 and friendedness at ages $10-11$ was statistically significant (estimate $=.01$, $p<.05)$. In addition, the indirect path from early disruptiveness to depressive symptoms via friendedness at ages $8-9$ and $10-11$ was significant at the trend level (estimate $=.01, p<.10$ ). Because there was no direct association between rejection and depressive symptoms-an association that, according to Kenny, Kashy, and Bolger (1998), must be established to assert that rejection mediates the relation between friendedness and depressive symptomsthere was no evidence for the alternate sequential mediation model (i.e., early behavior to friendedness at 8-9 to rejection at $10-11$ to adolescent depressive symptoms) or for mediation by peer rejection alone.

\section{Loneliness}

The full model for loneliness exhibited acceptable fit for the data, $\chi^{2}(8)=16.41, p<.05 ; \mathrm{CFI}=.98$, TLI $=$ .90 , RMSEA $=.04$. Adding a path linking early disruptiveness to peer rejection at ages 10-11, as suggested by the modification indexes, and trimming the nonsignificant paths in the model improved the fit, $\chi^{2}(18)=$ $17.08, n s ; \mathrm{CFI}=1.00$, TLI $=1.01$, RMSEA $=.00$ (see Figure 3). Associations of sex and maternal

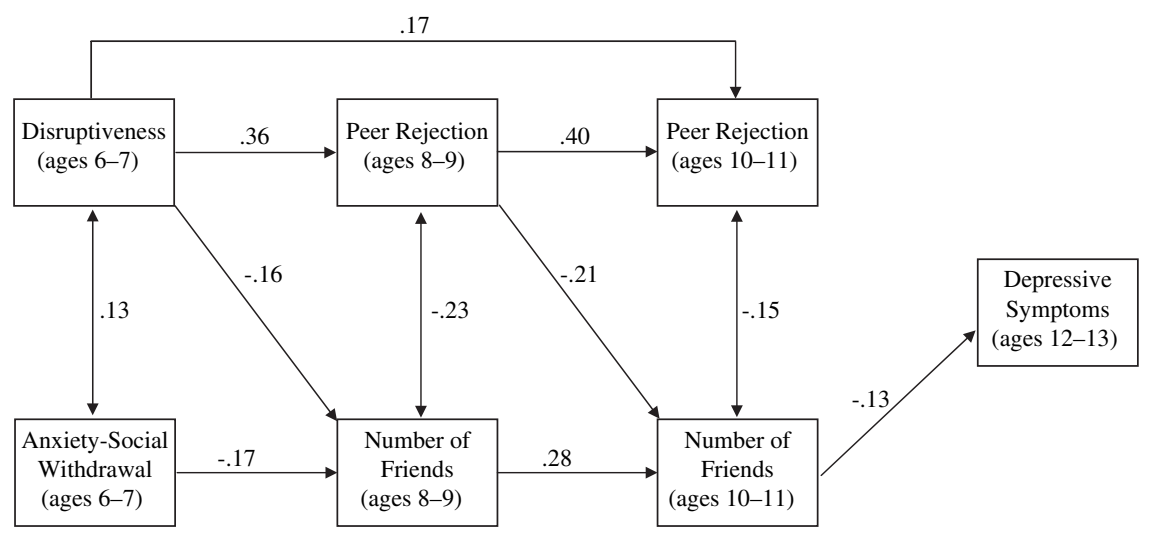

Figure 2. Results of the restricted model for depressive symptoms (standardized estimates). 
occupational prestige with early behavior were nearly identical to those observed in the depressive symptom analysis. In the current analysis, however, sex and maternal occupational prestige were unrelated to the outcome, adolescent loneliness.

As in the depressive symptom analysis, early disruptiveness was positively associated with both peer rejection variables and negatively associated with friendship at ages 8-9. Anxiety-social withdrawal was related only to the number of friends at ages 8-9. Again, the parameter estimates for these associations were virtually identical to those produced in the depressive symptom analysis.

In contrast to depressive symptoms, both age 1011 peer process variables were associated with loneliness. Peer rejection in later middle childhood was positively related to early-adolescent loneliness (estimate $=.23, p<.001$ ) whereas friendedness was negatively related to loneliness (estimate $=-.11$, $p<.05)$.

Finally, significant indirect paths linking early behavior to loneliness via the middle-childhood peer processes were observed. These paths provided support both for a single mediator pathway linking early behavior to loneliness via peer rejection and for the sequential mediation pathway. A significant indirect path emerged from disruptiveness to loneliness via peer rejection at ages $8-9$ and $10-11$ (estimate $=.03$, $p<.01)$. A trend-level path from disruptiveness to loneliness via peer rejection at ages $8-9$ and friendedness at $10-11$ (i.e., the sequential mediation model) also emerged (estimate $=.01, p<.10$ ). It should be noted that although this indirect pathway was significant only at the trend level, each of the individual paths composing the pathway was statistically significant, suggesting that we did not have adequate power to detect this effect reliably.

\section{Delinquency}

The full model for total delinquency exhibited acceptable fit for the data, $\chi^{2}(8)=22.49, p<.05$; $\mathrm{CFI}=.97, \mathrm{TLI}=.85, \mathrm{RMSEA}=.06$. Adding paths linking early disruptiveness to peer rejection at ages $10-11$ and to total delinquency at ages $12-13$, as suggested by the modification indexes, and trimming the nonsignificant paths in the model improved the fit, $\chi^{2}(17)=22.17, n s ; \mathrm{CFI}=.99$, TLI $=.97$, RMSEA $=$ .02 (see Figure 4). As in the depressive symptom and loneliness analyses, boys exhibited greater disruptiveness, and maternal occupational prestige was inversely related to disruptiveness and earlier peer rejection. Boys also reported more adolescent delinquency (estimate $=-.24, p<.001$ ).

Early disruptiveness was positively associated with both peer rejection variables and negatively associated with friendedness at ages 8-9. Anxietysocial withdrawal was related only to the number of friends at ages $8-9$. The parameter estimates for these associations were virtually identical to those produced in previous two analyses.

In contrast to the internalizing outcomes, neither age $10-11$ peer process variable was associated with adolescent delinquency. Only early disruptiveness significantly predicted adolescent delinquency (estimate $=.19, p<.01$ ). Because peer rejection and friendedness were unrelated to delinquency, no indirect paths linking early behavior to delinquency via the middle-childhood peer processes could be estimated.

\section{Discussion}

This is the first study designed to assess the dynamic interplay among two middle-childhood peer

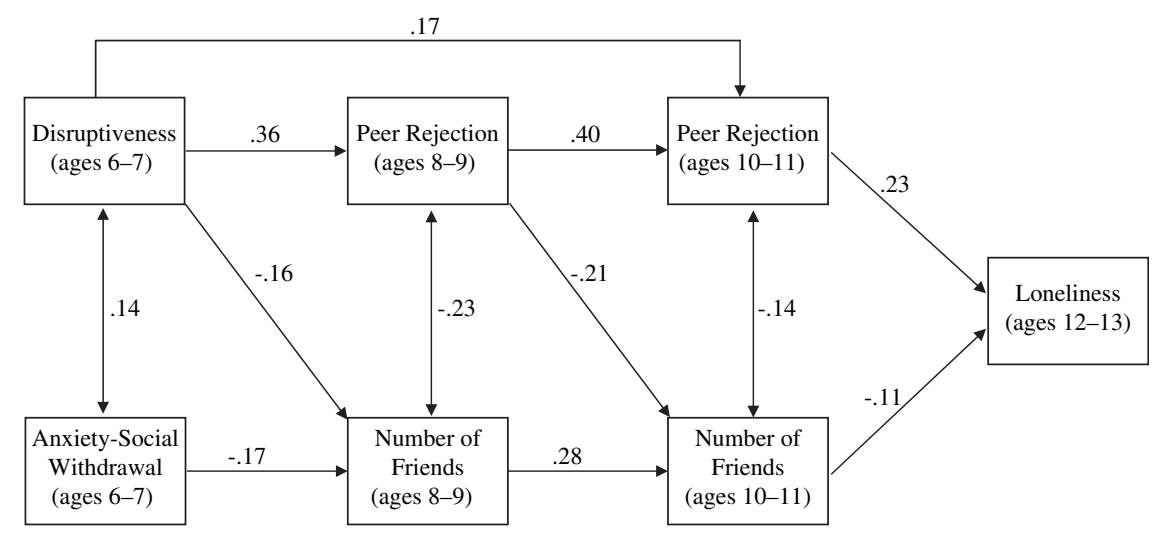

Figure 3. Results of the restricted model for loneliness (standardized estimates). 


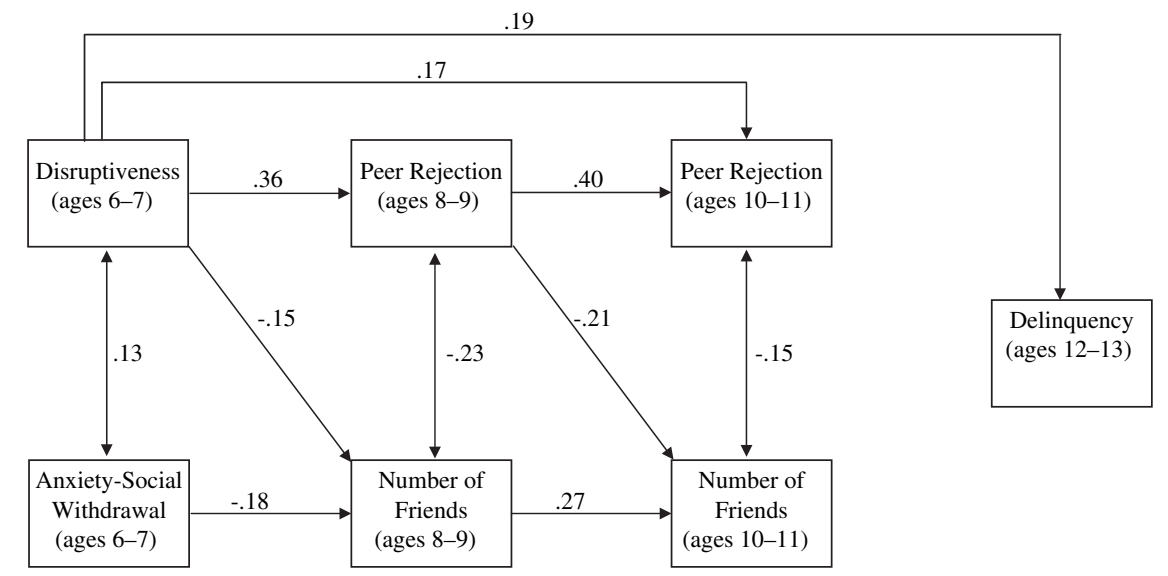

Figure 4. Results of the restricted model for delinquency (standardized estimates).

processes - peer rejection and reciprocal friendednessand their independent and mediated associations with three key developmental outcomes in early adolescence: depressive symptoms, loneliness, and delinquency. The results enhance our understanding of the importance of the timing of middle-childhood rejection and friendedness for early-adolescent adjustment and their specific roles with respect to internalizing and externalizing problems. In the following sections, we summarize and discuss our findings. First, we review the demographic associations with the childhood and adolescent individual adjustment and peer process variables. Next, we use the series of questions raised at the end of the Introduction to guide our discussion of the results of the mediation models we tested. Finally, we describe the study's limitations.

\section{Demographic Associations With Childhood and Adolescent Adjustment}

The associations among the demographic characteristics and other study variables were generally consistent with our expectations. Boys tended to be more disruptive and report more early-adolescent delinquency. Girls reported more early-adolescent depressive symptoms. Few sex differences, however, were observed in the middle-childhood peer processes after adjusting for early behavior. Our findings also support a link between SES and child well-being, although it should be noted that SES was represented by only one indicator, maternal occupational status. Lower occupational status was related to greater childhood disruptiveness and more early-adolescent depression, loneliness, and delinquency. Occupational status was also related to peer rejection, suggesting that children from more impoverished backgrounds are at heightened risk for rejection and thus for any negative outcomes precipitated by rejection.

\section{Does Early Behavior Predict Middle-Childhood Peer Relations?}

The current study's findings regarding the associations between early behavior and middle-childhood peer processes support our suggestion that earlychildhood behavior sets the stage for the subsequent development of group-level and dyadic peer relations. Disruptiveness was strongly linked to peer rejection and to having fewer friends at ages 8 and 9. Several studies (e.g., Miller-Johnson, Coie, Maumary-Gremaud, Bierman, \& Conduct Problems Prevention Research Group, 2002; Snyder, Prichard, Schrepferman, Patrick, \& Stoolmiller, 2004) have identified similar links, suggesting that their greater likelihood of rejection puts disruptive children at risk for a host of negative peer-related experiences that affect development, including victimization, deviant peer affiliation, and friendlessness (Boivin \& Hymel, 1997; Vitaro et al., 2005).

Also in line with previous studies (e.g., Boivin \& Hymel, 1997), early anxiety-social withdrawal was negatively related to the number of childhood friendships-relationships that form the foundation for friendships and romantic partnerships in adolescence and beyond (Masten et al., 1995). Anxietysocial withdrawal was, however, unrelated to peer rejection-a finding that is consistent with the results of previous studies (e.g., Ladd \& Troop-Gordon, 2003). Together, the findings for disruptiveness and anxiety-social withdrawal reflect the greater importance of disruptive behavior (relative to anxious and 
socially withdrawn behavior) as a predictor of peer difficulties early in childhood (Younger \& Piccinin, 1985). Still, these findings do not rule out the possibility that anxiety-social withdrawal becomes more closely related to rejection as children age. During adolescence, disruptive behaviors may become more normative and appealing as anxious and withdrawn behaviors become less attractive to peers (Younger \& Piccinin, 1985).

\section{How Are Peer Rejection and Friendedness Interrelated in Middle Childhood?}

Our results reveal substantial stability in rejection and friendedness despite changes in classroom composition from one year to the next. Indeed, in each model, earlier rejection was the strongest predictor of rejection at ages 10-11 and earlier friendedness was the strongest predictor of friendedness at ages 10-11. Thus, we can expect that children who experience rejection or low friendedness at the start of middle childhood, perhaps in association with early behavior problems, will be at heightened risk for rejection and low friendedness throughout this developmental stage. These findings are consistent with Brendgen et al. (2001), who found considerable stability in childhood peer acceptance. Furthermore, our findings extend this stability to friendedness, although friendedness appears to be less stable than rejection.

We also found that, although peer rejection at ages 10-11 was not predicted by earlier friendedness, friendedness at 10-11 was inversely related to earlier rejection. Three mechanisms may explain this temporal ordering of peer rejection and friendedness. First, early rejection may lead children to be denied access to social-skill-building group activities that facilitate friendship formation. In other words, rejected children may be excluded from social activities with classroom peers, such as games on the playground during recess, play dates, and birthday parties, that offer opportunities for friendship formation and the building of interpersonal skills that facilitate friendship formation. Alternately, early rejection may contribute to a sense of learned helplessness on the part of the rejected child that leads the child to cease his or her efforts to make friends. In addition, because of the social ostracism entailed by peer rejection (Hymel, Comfort, Schonert-Reichl, \& McDougall, 1996), few classmates are likely to befriend a rejected child once his or her negative reputation is established.

Another possible explanation for this finding related to the measurement of rejection and friendedness should be noted. As described previously, peer rejection was more stable than friendedness in the current study. Therefore, there was less variance left unexplained in the rejection variable than in the friendedness variable. After accounting for the variance in later rejection explained by earlier rejection and disruptiveness, there may have been too little variance remaining for earlier friendedness to predict reliably.

Do Middle-Childhood Rejection and Friendedness Act as Parallel or Sequential Mediators of the Link Between Early Behavior and Adolescent Adjustment?

The primary goal of the current study was to refine our understanding of the importance of the timing of rejection and friendedness in middle childhood for subsequent adjustment. In general, our findings provide support for the mediating hypothesis suggested by Nangle et al. (2003) with respect to internalizing behaviors. For both depression and loneliness, each of the paths constituting the sequentially mediated pathway from early disruptiveness to peer rejection at ages $8-9$, to friendedness at $10-11$, and to the outcome at ages $12-13$ was statistically significant. The overall sequential mediation pathway was also statistically significant for depression and was significant at the trend level for loneliness.

Still, for loneliness, the strongest indirect path from early behavior was via chronic peer rejection. Consistent with Kiesner (2002) and Boivin et al. (1994), rejection in middle childhood was directly related to loneliness. In contrast, early peer rejection was only related to depression indirectly through friendedness in the intervening years. Given the strong correlation between loneliness and depressive symptoms in our data, we were surprised that peer rejection was directly related to loneliness but not depressive symptoms. One possible explanation for this unexpected finding concerns the nature of the loneliness and depressive symptoms measures. The loneliness items were school specific and targeted both loneliness and social dissatisfaction. In contrast, the depression measure tapped general symptoms of poor well-being that were not specific to the school context or peer relations. Other authors have also failed to find an association between childhood rejection and adolescent depression (e.g., Ollendick et al., 1992).

Our results for the delinquency outcome analysis suggest that the sequential mediation pathway observed for the internalizing outcomes does not hold for externalizing outcomes. In contrast to the depressive symptoms and loneliness analyses, the delinquency analysis revealed no evidence of an indirect pathway linking early behavior to adolescent delinquency via middle-childhood peer rejection or friendedness. Indeed, neither rejection nor friendedness 
was directly associated with adolescent delinquency. Only early disruptiveness significantly predicted this externalizing outcome.

These results are consistent with studies in which peer rejection was found to play no role in the pathway linking early disruptive behavior to externalizing outcomes (Fergusson, Woodward, \& Horwood, 1999) and with studies in which friendedness played no beneficial role with respect to this pathway (Ladd \& Troop-Gordon, 2003). They are also in line with theoretical models that advocate that personal characteristics are the sole predictors of later antisocial behaviors, with peer experiences playing only an incidental role in this process (Caspi, Elder, \& Bem, 1987; Gottfredson \& Hirschi, 1991).

Before concluding that peer rejection makes no contribution to later externalizing problems, however, one has to consider the current study's timeframe and the type of externalizing problems that were examined. Previous studies have found no relation between peer rejection and delinquent behaviors or a negative association when (a) this association was examined over the course of early adolescence and (b) the outcome measure included items reflecting acts of minor delinquency and substance use that are fairly common among younger adolescents (Allen et al., 2005; Dishion et al., 1995). Peer rejection may still be positively related to externalizing problems before or after the early adolescent years. Peer rejection may also predict more extreme externalizing behaviors than were assessed in the current study.

Similarly, before concluding that friendedness plays no role in the process linking early behavior to adolescent externalizing problems, one has to consider other aspects of the friendship experience that may contribute to adolescent adjustment (Agnew, 1991; Berndt et al., 1999; Bukowski, Brendgen, \& Vitaro, in press). Other possible friendship-related mediators include exposure to deviant friends and subsequent deviancy training and modeling or low friendship quality and subsequent coercive processes. These additional peer experiences were not, however, included in the present study. In future studies, friend characteristics, such as deviancy, should be investigated as possible mediators of the link between early behavior and later externalizing problems before concluding that early behavior only predicts adolescent delinquency directly.

\section{Limitations of the Current Study}

Several issues limit our ability to interpret and draw causal conclusions from the current study's findings. First, we examined depressive symptoms and loneliness in separate analyses even though they are both part of the same broad spectrum of internalizing problems. We chose to examine and report our findings for these outcomes separately because depressive symptoms and loneliness are most often examined separately in the extant literature. Because depressive symptoms and loneliness are interrelated, however, we also tested a full model in which both outcomes were included. The direction and magnitude of the parameter estimates from the combined model did not differ from those identified in the separate models. This finding supported our decision to report the results of the separate analyses.

Second, although friendedness was related to both internalizing outcomes, these associations were small to moderate in size. It is possible that characteristics of the friends or the quality of the friendships moderated the association between the quantity of friends in middle childhood and adolescent adjustment. Some children may be involved in friendships that provide no developmental benefits or that are detrimental to development. Indeed, friendships can be associated with negative outcomes even when friends are well adjusted and friendship quality is high. For example, internalizing symptoms may be reinforced by dyadic interactions with well-adjusted friends whose sympathetic responses reward the internalizing behavior (Deater-Deckard, 2001; Heller \& Tanaka-Matsumi, 1999) or by interactions with equally maladjusted friends who model and reinforce inappropriate behaviors and attitudes (Rose, 2002). In other words, the beneficial effects of friendship may be qualified by friends' characteristics and the nature of the friends' interactions. Unfortunately, we could not investigate the role played by friendship quality in the current study because a reliable measure of friendship quality in middle childhood was not available at the time the study was conducted. This line of research should be followed up in future studies using currently available measures of friendship quality.

Another unaddressed friendship characteristic that may affect the strength of the association between friendedness and internalizing symptoms is friendship stability. To the degree that children's friendships remain stable over many years, the interpersonal processes that contribute to individual outcomes, such as depression and loneliness, may be reinforced and strengthened. The association between friendedness and individual outcomes among children who cannot or do not have the opportunity to form stable friendships may be weaker than among children with long-term friendships. Shorter term friendships may 
not contribute as strongly to individual well-being because these friendships are not characterized by the high levels of intimacy and mutual respect of longer lasting friendships. Therefore, we suggest that future studies consider the moderating role of stability.

Third, as in many long-term longitudinal studies, our data set has a high rate of missing data. Only about $30 \%$ of the study children have data for every variable. To the degree that the most troubled youth are also the most likely to have dropped out of the study, these missing data may have resulted in constrained variance on the outcome variables. Our attrition analysis, however, revealed no evidence that missingness on the early-adolescent outcome variables was predicted by any other study variable.

Finally, the present study used an ethnically homogenous sample of French Canadian children. It is unclear, therefore, whether these findings are applicable to a broad range of children from diverse backgrounds and communities. Future studies should address this limitation, examining the processes relating behavior, childhood peer rejection and friendship, and adolescent adjustment within and across different samples of youth.

\section{Summary and Conclusions}

Our findings suggest that the developmental consequences of risky peer processes are not limited to childhood. Early behavior problems appear to set the stage for peer rejection and low friendedness, which may then set youth on a trajectory toward internalizing difficulties, including elevated levels of depressed mood and feelings of loneliness. Consistent with Bagwell, Newcomb, and Bukowski (1998), we found that the nature of the associations of rejection and friendship with adolescent functioning differed depending on the targeted outcome. For loneliness, the strongest pathway from early behavior to adolescent adjustment was via peer rejection alone. For both internalizing outcomes, however, evidence for the sequential mediation model was observed, emphasizing the sequential role played by peer rejection and friendedness in middle childhood. In contrast, only a direct link between early behavior problems and early-adolescent delinquency was observed. There was no evidence of parallel or sequential mediation by childhood peer rejection and friendedness for this externalizing outcome. In sum, our findings indicate that although both rejection and friendship are predicted by early behavior problems, early peer rejection appears to prohibit the development of close, reciprocal friendships during the critical middlechildhood period for friendship formation-setting the stage for internalizing, but not externalizing, problems in early adolescence.

\section{References}

Agnew, R. (1991). The interactive effects of peer variables on delinquency. Criminology, 29, 47-72.

Alexander, C., Piazza, M., Mekos, D., \& Valente, T. (2001). Peers, schools, and adolescent cigarette smoking. Journal of Adolescent Health, 29, 22-30.

Allen, J. P., Porter, M. R., McFarland, F. C., Marsh, P., \& McElhaney, K. (2005). The two faces of adolescents' success with peers: Adolescent popularity, social adaptation, and deviant behavior. Child Development, 76, 747-760.

Asher, S. R., Hymel, S., \& Renshaw, P. D. (1984). Loneliness in children. Child Development, 55, 1456-1464.

Asher, S. R., \& Paquette, J. A. (2003). Loneliness and peer relations in childhood. Current Directions in Psychological Science, 12, 75-78.

Asher, S. R., Parker, J. G., \& Walker, D. L. (1996). Distinguishing friendship from acceptance: Implications for intervention and assessment. In W. M. Bukowski, A. F. Newcomb, \& W. W. Hartup (Eds.), The company they keep: Friendship in childhood and adolescence (pp. 366-405). New York: Cambridge University Press.

Asher, S. R., \& Wheeler, V. A. (1985). Children's loneliness: A comparison of rejected and neglected peer status. Journal of Consulting and Clinical Psychology, 53, $500-505$.

Bagwell, C. L., Newcomb, A. F., \& Bukowski, W. M. (1998). Preadolescent friendship and peer rejection as predictors of adult adjustment. Child Development, 69, 140-153.

Berndt, T. J. (2004). Children's friendships: Shifts over a half-century in perspectives on their development and their effects. Merrill-Palmer Quarterly, 50, 206-223.

Berndt, T. J., Hawkins, J. A., \& Jiao, Z. (1999). Influences of friends and friendships on adjustment to junior high school. Merrill-Palmer Quarterly, 45, 13-41.

Blishen, B. R., Carroll, W. K., \& Moore, C. (1987). The 1981 socioeconomic index for occupations in Canada. Canadian Review of Sociology and Anthropology, 24, 465-488.

Boivin, M., \& Hymel, S. (1997). Peer experiences and social self-perceptions: A sequential model. Developmental Psychology, 33, 135-145.

Boivin, M., Hymel, S., \& Hodges, V. E. (2001). Toward a process view of peer rejection and harassment. In J. Juvonen \& S. Graham (Eds.), Peer harassment in school: The plight of the vulnerable and victimized (pp. 265-289). New York: Guilford.

Boivin, M., Poulin, F., \& Vitaro, F. (1994). Depressed mood and peer rejection in childhood. Development and Psychopathology, 6, 483-498.

Boivin, M., Vitaro, F., \& Poulin, F. (2005). Peer relationships and the development of aggressive behavior in early childhood. In R. E. Trembay, W. W. Hartup, \& J. J. Archer (Eds.), Developmental origins of aggression (pp. 376-397). New York: Guilford. 
Brendgen, M., Vitaro, F., Bukowski, W. M., Doyle, A. B., \& Markiewicz, D. (2001). Developmental profiles of peer social preference over the course of elementary school: Associations with trajectories of externalizing and internalizing behavior. Developmental Psychology, 37, 308-320.

Bukowski, W. M., Brendgen, M., \& Vitaro, F. (2007). Peers and socialization: Effects on externalizing and internalizing problems. In J. Grusec \& P. Hastings (Eds.), Handbook of socialization: Theory and research (pp. 355381). New York: Guilford.

Bukowski, W. M., \& Hoza, B. (1989). Popularity and friendship: Issues in theory, measurement, and outcome. In T. Berndt \& G. Ladd (Eds.), Peer relationships in child development (pp. 15-45). New York: Wiley.

Bukowski, W. M., Pizzamiglio, M. T., Newcomb, A. F., \& Hoza, B. (1996). Popularity as an affordance of friendship: The link between group and dyadic experiences. Social Development, 5, 189-202.

Caspi, A., Elder, G. H., \& Bem, D. J. (1987). Moving against the world: Life-course patterns of explosive children. Developmental Psychology, 23, 308-313.

Coie, J. D., \& Dodge, K. A. (1998). Aggression and antisocial behavior. In W. Damon \& N. Eisenberg (Eds.), Handbook of child psychology: Vol. 3. Social, emotional, and personality development (5th ed., pp. 779-862). New York: Wiley.

Coie, J. D., Dodge, K. A., \& Coppotelli, H. (1982). Dimensions and types of social status: A cross-age perspective. Developmental Psychology, 18, 557-570.

Deater-Deckard, K. (2001). Annotation: Recent research examining the roles of peer relationships in the development of psychopathology. Journal of Child Psychology and Psychiatry, 42, 565-579.

Demir, M., \& Urberg, K. A. (2004). Friendship and adjustment among adolescents. Journal of Experimental Child Psychology, 88, 68-82.

DeRosier, M. E., Kupersmidt, J. B., \& Patterson, C. J. (1994). Children's academic and behavioral adjustment as a function of the chronicity and proximity of peer rejection. Child Development, 65, 1799-1813.

Dishion, T. J., Capaldi, D. M., Spracklen, K. M., \& Li, F. (1995). Peer ecology of male adolescent drug use. Development and Psychopathology, 7, 803-824.

Fergusson, D. M., Woodward, L. J., \& Horwood, L. J. (1999). Childhood peer relationship problems and young people's involvement with deviant peers in adolescence. Journal of Abnormal Child Psychology, 27, 357-370.

Fundulis, T., Berney, T. P., Kolvin, O., Famuyiva, O. O., Barrett, T., Bhate, S., et al. (1991). Reliability and validity of two rating scales in the assessment of childhood depression. British Journal of Psychiatry, 159, 36-40.

Gifford-Smith, M. E., \& Brownell, C. A. (2003). Childhood peer relationships: Social acceptance, friendships, and peer networks. Journal of School Psychology, 41, 235-284.

Gottfredson, M. R., \& Hirschi, T. (1991). Three facts and their implications for research on crime. In G. Albrecht, O. Hans-Uwe, S. Karstedt-Henke, \& K. Bollert (Eds.), Social prevention and the social sciences: Theoretical con- troversies, research problems, and evaluation strategies (pp. 525-535). Oxford, UK: Walter De Gruyter.

Heller, M. C., \& Tanaka-Matsumi, J. (1999). A sequential analysis of depressive behaviors within adolescent peer interactions. Journal of Psychopathology and Behavioral Assessment, 21, 249-273.

Hindelang, M. J., Hirschi, T., \& Weiss, J. (1981). Measuring delinquency. Beverly Hills, CA: Sage.

Hu, L., \& Bentler, P. M. (1999). Cutoff criteria for fit indexes in covariance structure analysis: Conventional criteria versus new alternatives. Structural Equation Modeling, 6, $1-55$.

Hymel, S., Comfort, C., Shonert-Reichl, K., \& McDougall, P. (1996). Academic failure and school dropout: The influence of peers. In J. Juvonen \& K. R. Wentzel (Eds.), Social motivation: Understanding children's school adjustment. Cambridge studies in social and emotional development (pp. 313-345). New York: Cambridge University Press.

Kenny, D. A., Kashy, D. A., \& Bolger, N. (1998). Data analysis in social psychology. In D. T. Gilbert, S. T. Fiske, \& G. Lindzey (Eds.), The handbook of social psychology (pp. 233-265). New York: McGraw-Hill.

Kiesner, J. (2002). Depressive symptoms in early adolescence: Their relations with classroom problem behavior and peer status. Journal of Research on Adolescence, 12, $463-478$.

Klein, M. W. (1989). Cross-national research in self-reported crime and delinquency. Dordrecht, Netherlands: Kluwer.

Kovacs, M. (1992). Children's Depression Inventory (CDI) manual. Toronto, Canada: Multi-Health Systems.

Lacourse, E., Nagin, D. S., Tremblay, R. E., Vitaro, F., \& Claes, M. (2003). Developmental trajectories of boys delinquent group membership and facilitation of violent behaviors during adolescence. Development and Psychopathology, 15, 183-197.

Ladd, G. W. (2006). Peer rejection, aggressive or withdrawn behavior, and psychological maladjustment from ages 5 to 12: An examination of four predictive models. Child Development, 77, 822-846.

Ladd, G. W., \& Troop-Gordon, W. (2003). The role of chronic peer difficulties in the development of children's psychological adjustment problems. Child Development, 74, 1344-1367.

Laird, R. D., Jordan, K. Y., Dodge, K. A., Pettit, G. S., \& Bates, J. E. (2001). Peer rejection in childhood, involvement with antisocial peers in early adolescence, and the development of externalizing behavior problems. Development and Psychopathology, 13, 337-354.

LeBlanc, M., \& Fréchette, M. (1989). Male criminal activity from childhood through youth: Multilevel and developmental perspective. New York: Springer-Verlag.

Lopez, C., \& DuBois, D. L. (2005). Peer victimization and rejection: Investigation of an integrative model of effects on emotional, behavioral, and academic adjustment in early adolescence. Journal of Clinical Child and Adolescent Psychology, 34, 25-36.

Masten, A. S., Coatsworth, J. D., Neeman, J. D., Gest, S. D., Tellegen, A., \& Garmezy, N. (1995). The structure and 
coherence of competence from childhood through adolescence. Child Development, 66, 1635-1659.

McDougall, P., Hymel, S., Vaillancourt, T., \& Mercer, L. (2001). The consequences of childhood peer rejection. In M. R. Leary (Ed.), Interpersonal rejection (pp. 213-250). New York: Oxford University Press.

Miller-Johnson, S., Coie, J. D., Maumary-Gremaud, A., Bierman, K., \& Conduct Problems Prevention Research Group. (2002). Peer rejection and aggression and early starter models of conduct disorder. Journal of Abnormal Child Psychology, 30, 217-230.

Muthén, L., \& Muthén, B. (2004). Mplus user's guide (3rd ed). Los Angeles: Authors.

Nangle, D. W., Erdley, C. A., Newman, J. E., Mason, C. M., \& Carpenter, E. M. (2003). Popularity, friendship quantity, and friendship quality: Interactive influences on children's loneliness and depression. Journal of Clinical Child and Adolescent Psychology, 32, 546-555.

Ollendick, T. H., Weist, M. D., Borden, M. C., \& Greene, R. W. (1992). Sociometric status and academic, behavioral, and psychological adjustment: A five-year longitudinal study. Journal of Consulting and Clinical Psychology, 60, 80-87.

Panak, W. F., \& Garber, J. (1992). Role of aggression, rejection, and attributions in the prediction of depression in children. Development and Psychopathology, 4, 145-165.

Parker, J. G., \& Asher, S. R. (1987). Peer relations and later personal adjustment: Are low-accepted children at risk? Psychological Bulletin, 102, 357-389.

Parker, J. G., \& Asher, S. R. (1993). Friendship and friendship quality in middle childhood: Links with peer group acceptance and feelings of loneliness and social dissatisfaction. Developmental Psychology, 29, 611-621.

Parker, J. G., Saxon, J. L., Asher, S. R., \& Kovacs, D. M. (1999). Dimensions of children's friendship adjustment: Implications for understanding loneliness. In K. J. Rotenberg \& S. Hymel (Eds.), Loneliness in childhood and adolescence (pp. 201-221). Cambridge, UK: Cambridge University Press.

Patterson, G. R., Dishion, T. J., \& Yoerger, K. (2000). Adolescent growth in new forms of problem behavior: Macro- and micro-peer dynamics. Prevention Science, 1, $3-13$.
Prinstein, M. J., \& Cillessen, A. H. N. (2003). Forms and functions of adolescent peer aggression associated with high levels of peer status. Merrill-Palmer Quarterly, 49, $310-342$.

Rose, A. J. (2002). Co-rumination in the friendships of girls and boys. Child Development, 73, 1830-1843.

Rubin, K. H., Bukowski, W., \& Parker, J. G. (1998). Peer interactions, relationships, and groups. In W. Damon \& N. Eisenberg (Eds.), Handbook of child psychology: Vol. 3. Social, emotional, and personality development (5th ed., pp. 610-700). New York: Wiley.

Rubin, K. H., Moller, L., \& Emptage, A. (1986). The Preschool Behavior Questionnaire: A useful index of behavior problems in elementary school-age children? Canadian Journal of Behavioral Sciences, 19, 86-100.

Snyder, J., Prichard, J., Schrepferman, L., Patrick, M. R., \& Stoolmiller, M. (2004). Child impulsiveness-inattention, early peer experiences, and the development of early onset conduct problems. Journal of Abnormal Child Psychology, 32, 579-594.

Sullivan, H. S. (1953). The interpersonal theory of psychiatry. New York: Norton.

Tremblay, R. E., Loeber, R., Gagnon, C., Charlebois, P., Larivée, S., \& LeBlanc, M. (1991). Disruptive boys with stable and unstable high fighting behavior patterns during junior elementary school. Journal of Abnormal Child Psychology, 19, 285-300.

Tremblay, R. E., Vitaro, F., Gagnon, C., Piché, C., \& Royer, N. (1992). A prosocial scale for the Preschool Behavior Questionnaire: Concurrent and predictive correlates. International Journal of Behavioral Development, 15, 227 245.

Vitaro, F., Brendgen, M., \& Wanner, B. (2005). Patterns of affiliation with delinquent friends during late childhood and early adolescence: Correlates and consequences. Social Development, 14, 82-108.

Vitaro, F., Tremblay, R. E., Kerr, M., Pagani, L. S., \& Bukowski, W. M. (1997). Disruptiveness, friends' characteristics, and delinquency: A test of two competing models of development. Child Development, 68, 676-689.

Younger, A. J., \& Piccinin, A. M. (1985). Children's recall of aggressive and withdrawn behaviors: Recognition memory and likability judgments. Child Development, $60,580-590$. 